\title{
Inspiration, Strategies and Insight for Learning \\ Programming Language
}

\author{
Gajendra Sharma and Toshika Ojha \\ Department of Computer Science \& Engineering \\ Kathmandu University (KU) \\ Dhulikhel, Nepal \\ E-mail: gajendra.sharma@ku.edu.np
}

Received: June 6, 2020 Accepted: Sep. 7, $2020 \quad$ Published: April 1, 2021

doi:10.5296/jmr.v13i2.17634 URL: https://doi.org/10.5296/jmr.v13i2.17634

\begin{abstract}
This study explores how the first-year undergraduate students in School of Engineering, Kathmandu University learns their very first programming language i.e. C programming. The students were requested to response to an online questioner, where they were asked about their perception about the programming language they are learning, their motivation on learning that particular language and their strategy on preparing for the subject. Student's concept on C programming and their approach for preparing for the exam are categorized. Our results show what kind of different strategies they use to learn this particular programming language. Additionally, the insights of this paper point that learning theory of programming and practicing programming goes hand in hand in $\mathrm{C}$ programming course and the focus here is on learning difficult topics which involves investigating students perceptions and conceptions of causality in relation to learning difficulties (Berglund et al., 2009). This study is intended to be helpful for future teachers and students in programming courses in Nepal.
\end{abstract}

Keywords: School of Engineering, motivation, strategy, C programming, perception, learning difficulties 
Introduction

2021, Vol. 13, No. 2

How do novice students learn programming when they first join university is a worldwide concern (Tshering et al., 2017) . It is found that the high dropout rate of CS students on the first year is due to difficulty in understanding the concept of computer programming. Computer Programming is a cognitively challenging subject and appears to be the most difficult aspect to master in dealing with computers (Chan, 2012). In developing countries like Nepal, many of the beginner students in IT doesn't have any previous experience in programming and also unlike the students grown up on big cities majority of Nepalese living in rural areas didn't have any access to the internet if we only turn back and see 5 years before now. Even now when the internet is available in most part of the country schools at high schools are unable to access it. Considering this, getting to know how these beginner students adopt different learning approaches has become my matter of interest. So, I aim to get insights on these student's learning Practices and get a good starting point for future research on those that seem to lead to success in this context.

Programming subject is mostly known as a difficult subject to learn. Many students claim to dislike programming subject and not be able to do programming well which results on high dropout and failure rates in introductory programming subjects in Universities and High Schools. Students have difficulties to master in Programming subjects with all required competencies and skills initially. The computer science educators are being more concerned about the lack of Programming Comprehension of new computer science students since it is a cognitively challenging subject and appears to be the most difficult aspect to master in dealing with computers. The teachers usually expect the beginner undergraduate students to practice the use of the programming tools by undertaking exercises. This method may have worked at the past when they were very few competent students on the field of programing. But now, with IT industry taking hype many students rush into the programing field with their different individual motivations. So, this study is also concerned with evaluating or analyzing these teaching methods once again.

The motivation of students is a key issue if they are to learn and to succeed in any academic task, the student must be motivated and they must want to successes (Jenkins, 2001). This is especially true in a practical disciple such as programming, students must be motivated to spend time practicing, even when there is no explicit assessment credit available.

However, an attempt to describe why student might value learning author Fallows and Ahmet proposed an informal list:

- The learner's desire to please the teacher

- The learner's perceived need for the material being presented

- The learner's degree of interest in the subject material

- The philosophical values and beliefs of the learner

- The incentives and rewards that are expected to accrue form the learning (Jenkins, 2001) 
Since, the nature of computer programming is cognitively challenging it is important to conduct a sort of investigation on the perceptions of students about their programming learning Experience and also the learning strategies they use in order to identify the areas or topics that are perceived as challenging by the students and also to find the problems in learning environment

\section{Research Objectives}

This research study has following objectives:

1. To understand the motivation of first year undergraduate students on learning computer programming

2. To know the learning strategy of Undergraduate students for computer programming

\section{Literature Review}

Bhutan had conducted a research targeted for knowing about the Learning strategies the first year IT students of Royal University of Bhutan applied to build their concept on C programming and prepare for the exams (Tshering et al., 2017). They closely monitored student's learning techniques and also evaluated them by taking three examinations in total. They included questions like how much time they spend learning programing together with one or more than one student in collaborative environment and how much time students spend coding alone, coding in a group or watching someone coding.

As there is exam oriented educational system, they even studied about how students prepare for their exams. And they found that some of the students only rely on the study materials provided by the teacher such as lecture slides and sample programs. Some of them preferred to understand the theory at first and then practicing the coding by themselves. These kinds of students were those who performed really well. They even found some of the students seeking help from their friend or surfing the internet. As they monitored the student's progress making depending upon the exams the students gave under the authors supervision, they found that the students who spend more time on group studies than coding alone or watching someone code. They also concluded that the students who did really well on not studying for much time must have previous background on programming. The other students who study for long hours but didn't do well in exams must be totally new in programming. This all make it clear that programming can get really tough for those who are new to the field and they should really be aware about their strategies when they are spending time in study.

Yacob et al., (2012) had conducted a research on accessing the level of motivation in learning programming among engineering students. They formed or divided their research questions into two parts. The first part asking about the learning motivations and programming learning of the students and the second part included questions reflecting student's expectations about the course. In first part they analyzed the factors that are important in motivating student learning and how does those factor affect computer programming learning while in second part which was about analyzing students expectation about learning programing they asked on the behalf of students expectations 
like if programming can be more fun, user friendly and entertaining, or if the Programming course can be easily programmed or programming course can never involve them on writing using text or command or it can be implemented using interesting learning style and their expectation that programming course can bring them further on software programming development. They prepared the questionnaires in three sections including demographic information, Programming background and programming perceptions of the students. After the survey they implemented an interview session among two groups high performing and low performing to find out the reasons for the motivation.

The authors carried out t-test to calculate strength of each factors on the first two research questions (Yacob et al., 2012). They found that both intrinsic and extrinsic factors, have strong positive motivating effect on learning and also punishment, reward and recognition had greatest motivational effect on the students. They found quite similar results for the factors that are student's, motivation or learning and factors that are student's motivation for learning programming.

\section{Method}

\section{Participants}

In Kathmandu University, School of Engineering, the first-year undergraduate student of every faculty needs to study a course on Computer Programming called C-programming. So, the participants here were the first-year engineering students from Kathmandu University. They were categorized into two groups. Group one was of students who have joined for non-IT course of Engineering and another group was the students who have joined for any relevant the course on IT.

\section{Instruments}

A questioner was prepared for online survey. The same questioner was prepared for both groups containing open ended and closed ended questions. In the closed ended questions, the students were asked questions like Q1, Q2, Q3, and Q7.

Q1: Do you enjoy learning C-programming?

Q2: If this subject was optional, would you choose this subject?

Q3: what motivates you to learn C-programming?

Q4: Do you think this subject will help you if you are from not IT field?

Q5: Do you have pervious programming background?

Q6: How do you learn C-Programming?

Q7: How do you think C-programming will help you in future?

Q8: Have you ever felt like dropping out because of this subject?

In closed questions, basically it is intended to know the student's motivation on learning C-programming and their perception towards it. In open ended questions main focus was 
on knowing the student's strategies on learning C Programming. Where we get them answer two questions.

Q1: How you define C Programming on your own words?

Q2: Can you share how you have prepared for the course?

\section{Results}

\section{Student's motivation on learning C programming}

From Group A, 30\% of the students were studying the subject just because it was on the course, and they wouldn't choose this subject if it was optional.50\% of the students has found the subject useful but difficult to understand the concept. And 20\% of the students found the subject very interesting and are able to understand the concept very well. And they enjoy the subject. From group B, $55 \%$ of the students feels that they need to study this subject well because they are from IT background, $30 \%$ of the students enjoys the subject and challenge themselves everyday while $15 \%$ of the students find the subject really difficult and even think of dropping out.

\section{Students strategy on learning C programming}

Depending upon the answers presented by the students, for the open-ended questions, the strategies used by them has been categorized into six categories and the result is displayed as below.

\section{Learning Strategy of Group-A students}

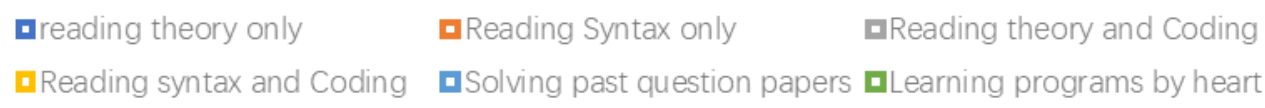

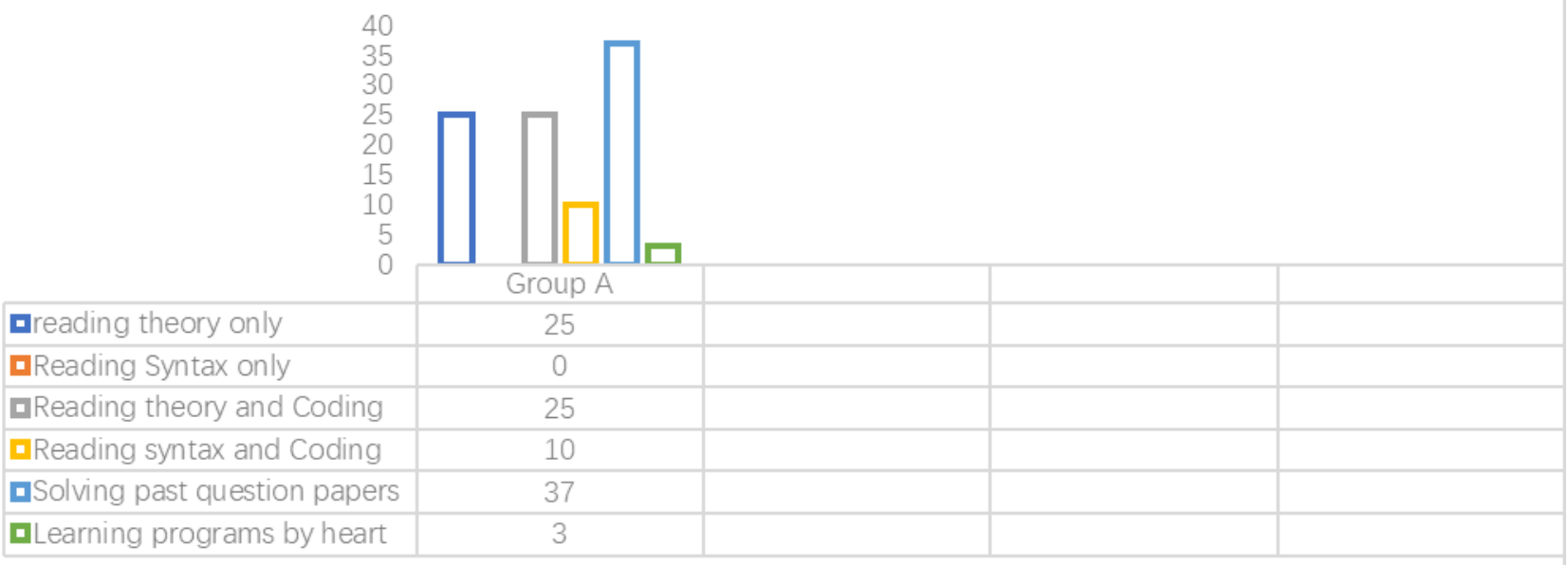




\section{Learning Strategy of Group-B students}

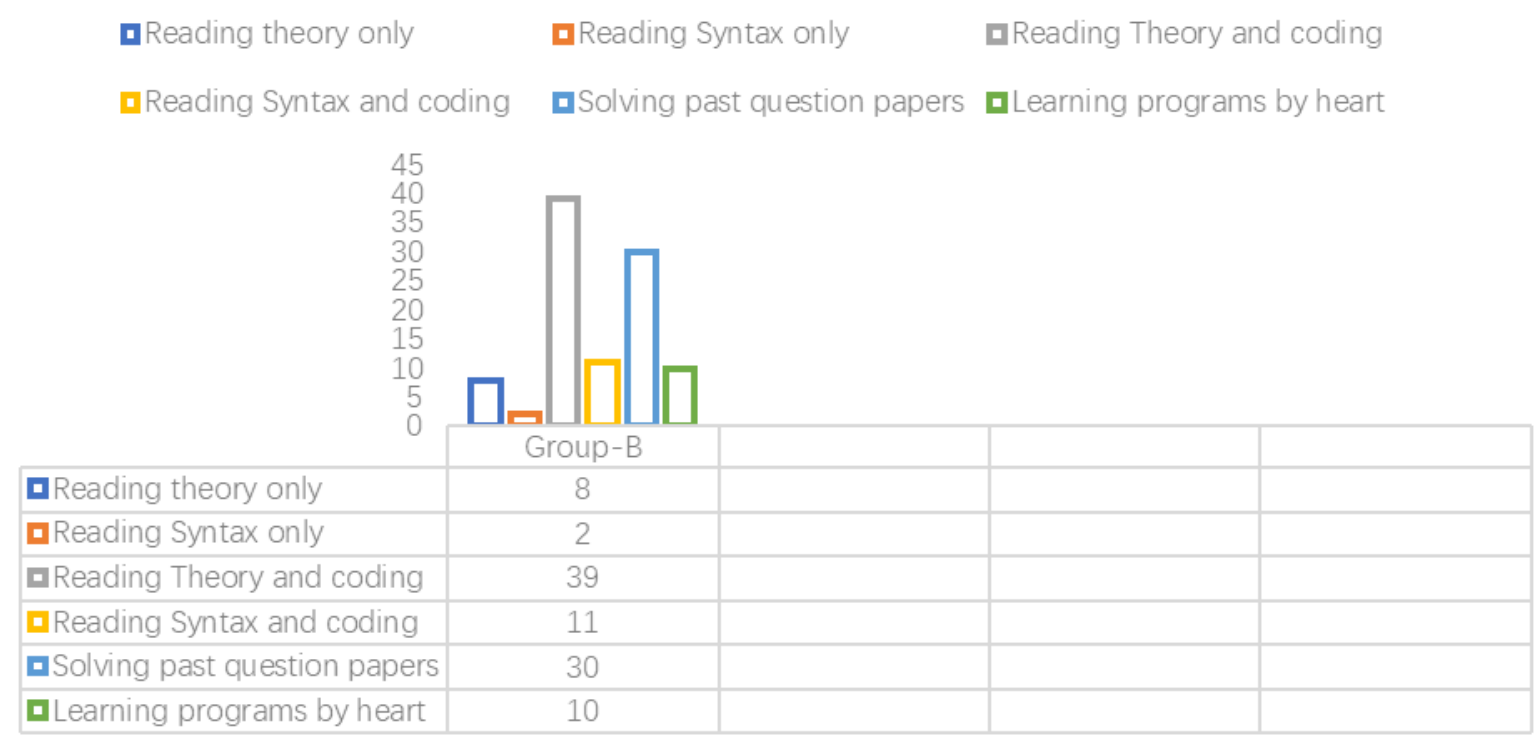

\section{Discussion}

This study gives glimpses on how the first-year undergraduate students at School of Engineering, Kathmandu University tackle their first programming course. The aim of this study has been to gain insights in how programming is being learnt in developing countries like Nepal. And the ultimate aim of this study is to offer advice to educational institutions, teachers and students on how to enhance teaching and learning of programming so that we sensibly uplift the IT industry in Nepal.

\section{References}

Berglund, A., Eckerdal, A., Pears, A., East, P., Kinnunen, P., Malmi, L., ... Thomas, L. (2009). Learning Computer Science: Perceptions, Actions and Roles. European Journal of Engineering Education, 34(4), 327-338. https://doi.org/10.1080/03043790902989168

Chan Mow, I. T. V. (2012). Investigative Study on NUS Computer Programming Students' Perceptions of Their Computer Programming Experience: Some Preliminary Findings. International Journal of Information Systems and Computer Sciences, 1(1), 12-21. https://doi.org/10.1080/02786826.2011.640365

Jenkins, T. (2001). The Motivation of Students of Programming. ACM SIGCSE Bulletin, 33(3), 53-56. https://doi.org/10.1145/507758.377472

Tshering, P., Lhamo, D., Yu, L., \& Berglund, A. (2017). How Do First Year Students Learn C Programming in Bhutan? Proceedings - 5th International Conference on Learning and 
Teaching in Computing and Engineering, LaTiCE 2017, 25-29. https://doi.org/10.1109/LaTiCE.2017.12

Yacob, A., Computer, F., \& Terengganu, K. (2012). Assessing Level of Motivation in Learning. The International Conference on Informatics and Applications (ICIA2012), (January), 425-432. 